\title{
Characterization of Constitutive and Putative Differentially Expressed mRNAs by Means of Expressed Sequence Tags, Differential Display Reverse Transcriptase-PCR and Randomly Amplified Polymorphic DNA-PCR from the Sand Fly Vector Lutzomyia longipalpis
}

\author{
JM Ramalho-Ortigão, P Temporal, SMP de Oliveira* , AF Barbosa*, \\ ML Vilela*, EF Rangel*, RP Brazil**, YM Traub-Cseko/ ${ }^{+}$
}

\begin{abstract}
Departamento de Bioquímica e Biologia Molecular *Departamento de Entomologia, Instituto Oswaldo Cruz, Av. Brasil 4365, 21045-900 Rio de Janeiro, RJ, Brasil **Centro de Pesquisas Rene Rachou-Fiocruz,

Belo Horizonte, MG, Brasil
\end{abstract}

\begin{abstract}
Molecular studies of insect disease vectors are of paramount importance for understanding parasite-vector relationship. Advances in this area have led to important findings regarding changes in vectors' physiology upon blood feeding and parasite infection. Mechanisms for interfering with the vectorial capacity of insects responsible for the transmission of diseases such as malaria, Chagas disease and dengue fever are being devised with the ultimate goal of developing transgenic insects. A primary necessity for this goal is information on gene expression and control in the target insect. Our group is investigating molecular aspects of the interaction between Leishmania parasites and Lutzomyia sand flies. As an initial step in our studies we have used random sequencing of cDNA clones from two expression libraries made from head/thorax and abdomen of sugar fed $\mathrm{L}$. longipalpis for the identification of expressed sequence tags (EST). We applied differential display reverse transcriptase-PCR and randomly amplified polymorphic DNA-PCR to characterize differentially expressed mRNA from sugar and blood fed insects, and, in one case, from a L. (V.) braziliensis-infected L. longipalpis. We identified 37 cDNAs that have shown homology to known sequences from GeneBank. Of these, 32 cDNAs code for constitutive proteins such as zinc finger protein, glutamine synthetase, $G$ binding protein, ubiquitin conjugating enzyme. Three are putative differentially expressed cDNAs from blood fed and Leishmaniainfected midgut, a chitinase, a V-ATPase and a MAP kinase. Finally, two sequences are homologous to Drosophila melanogaster gene products recently discovered through the Drosophila genome initiative.
\end{abstract}

Key words: sand fly - Lutzomyia longipalpis - Leishmania - differential - display - expressed sequence tags

Even at the dawn of the XXI century leishmaniasis is still one of the most important tropical diseases in the world, afflicting countries located mostly in Latin America, Africa and Asia with approximately two million new cases every year (www.who.int/ctd/html). These include 500 thousand cases per year of visceral leishmaniasis (VL), the deadliest form of the disease. In Brazil, as is the case for the rest of South America, Lutzomyia longipalpis is considered the main vector of the visceral disease, caused by the parasite Leishmania (L.) chagasi.

Financial support: $\mathrm{CNPq}$

${ }^{+}$Corresponding author. Fax: +55-21-590-3495. E-mail: ytraub@gene.dbbm.fiocruz.br

Received 12 May 2000

Accepted 15 August 2000
Despite our current knowledge of both the epidemiology of the disease and their vectors, very little is known about molecular mechanisms behind the interactive relationships between Leishmania parasites and sand flies. One way to better understand how these relationships occur is through the analysis and characterization of target molecules within the vector. Several studies (Pimenta et al. 1994, Sacks et al. 1994, 2000, Saraiva et al. 1995, Butcher et al. 1996, Mahoney et al. 1999) regarding the role played by lipophosphoglycan (LPG) molecules on the surface of Leishmania pointed to a lectin-like receptor putatively localized on the sand fly midgut epithelial cells. Dillon and Lane (1999) reported the detection of a $65 \mathrm{kDa}$ microvillar protein that participates in the binding of LPG to the midgut. Though these authors have clearly shown the fundamental role lipophosphoglycan binding has in determining the susceptibility of insects to Leishmania, further studies are 
necessary to identify other eventual target molecules.

Recently, Charlab et al. (1999) have identified nine full length cDNA molecules in L. longipalpis salivary gland, five of which are thought to participate in blood aquisition. Together with the previously characterized maxadilan peptide (Lerner et al. 1991, Lerner \& Shoemaker 1992) shown to exarcebate the inflamatory response (Soares et al. 1998) and to possibly have a role in Leishmania infectivity in the vertebrate host (Warburg et al. 1994), these proteins are potentially important in Leishmania-sand fly interaction and in the ability of the insect to function as a vector.

Similar studies using the malaria mosquito vector, Anopheles gambiae, have led to the characterization of various digestive and other gut-specific proteins. Enzymes such as trypsin, V-ATPase, maltase, non-trypsin serine protease, carboxypeptidase A and mucin from this mosquito have already been identified (Muller et al. 1995, Dimopoulos et al. 1996, Edwards et al. 1997, Shen et al. 1999). Some of these proteins have important roles during Plasmodium invasion of the midgut. Knowing how they are regulated may help develop new approaches to fight malaria (Billingsley 1994, O'Brochta \& Atkinson 1997, Shen et al. 1999).

Both mosquito and sand fly gut-specific promoters can be applied in various strategies to fight parasites within the insect midgut. These strategies include expression of molecules that can be either specifically toxic to the parasite or which may be able to block the interaction of the parasite with the midgut epithelia, thus halting obligatory steps for parasite survival in the vector. The characterization of promoters and genes can be achieved through the identification of expressed sequenced tags (EST). EST analysis has been used to understand molecular aspects of a given organism (e.g., P. falciparum, Chakrabarti et al. 1994) or to help in a gene discovery/genome mapping program (e.g., Schistosoma mansoni, Rabelo et al. 1997).

Based on our interest in studying the molecular events taking place in the sand fly $L$. longipalpis upon blood feeding and infection, the characterization of EST as well as gut-specific genes and promoters may help us shed some light on mechanisms behind the molecular interaction of these vectors and Leishmania parasites.

We compared RNA expression in the midgut from blood fed and sugar fed, or infected and noninfected female insects by means of differential display reverse transcriptase-polymerase chain reaction (DDRT-PCR) and by randomly amplified polymorphic DNA-polymerase chain reaction (RAPD-PCR). We have also used direct sequenc- ing of clones isolated from two cDNA libraries from abdomen and head/thorax of sugar fed insects to generate EST data for L. longipalpis. In this paper we present results related to the positive identification of 37 different cDNA molecules. They include 32 EST from expression libraries of sugar fed females of L. longipalpis and three cDNAs obtained from DDRT-PCR shown by adult female insects upon blood feeding or infection with L. (V.) braziliensis.

\section{MATERIALS AND METHODS}

Insects - L. longipalpis sand flies were obtained from the following sources: (a) for the construction of the expression libraries, the insects were obtained from the colony maintained by the Department of Entomology, IOC-Fiocruz. These were reared as previously described (Wermelinger et al. 1987). Adult insects were given a sugar meal upon eclosion from pupae stage with a cotton embedded on a sucrose-based solution; (b) for DDRT and RAPDPCR experiments we utilized midguts from insects captured at the Lapinha Cave, State of Minas Gerais, Brazil. These insects were offered a blood meal even though some appeared to have had a prior blood meal of unknown origin. For the blood meal we used a mouse or hamster anesthesized with a 5\% ketamine (Ketalar ${ }^{\mathrm{TM}}$, Park Davis) s.c. injection (0.2-0.3 ml per animal). Fully engorged females were separated for dissection approximately $36-40 \mathrm{~h}$ postfeeding. Dissections of midguts were done under a Zeiss stereoscopic microscope. Blood present during dissection was washed in 1X PBS solution treated with $0.1 \%$ diethilpyrocarbonate (Sigma Chemical Co., St. Louis. MO, USA); (c) a third set of experiments was carried out with $L$. (V.) braziliensis (MHOM/BR/ 75/M2903)-infected L. longipalpis (colony-reared). For this procedure three day old female insects were artificially fed, through chick skin membrane, an infective blood meal containing $10^{7}$ promastigote/ $\mathrm{ml}$. After five days postinfection insects were dissected and checked for the presence of parasite. Infected midguts were used for RNA isolation.

Expression libraries - For the generation of the expression libraries we used female sand flies exclusively fed on sugar. Total RNA from head/thorax and abdomen was extracted with the TRIzol ${ }^{\mathrm{TM}}$, reagent (Life Technologies Inc., Grand Island, NY, USA) according to manufacturer's protocol. cDNA was obtained using the First Strand cDNA Synthesis Kit (Amersham-Pharmacia Biotech) and cloned into $\lambda Z A P$ vector (Stratagene, La Jolla, CA, USA). Insert-carrying phagemids excized from libraries were submitted to one round of sequencing.

Differential display - RNA extracted from groups of 10 to 20 midguts in $1.5 \mathrm{ml}$ microcentri- 
fuge tube containing $0.5 \mathrm{ml}$ TRIzol ${ }^{\mathrm{TM}}$ reagent was kept at $-20^{\circ} \mathrm{C}$. For synthesis of first strand cDNA molecules $100 \mathrm{ng}$ of total RNA isolated from sugar and blood fed midguts of $L$. longipalpis females was used in a RT-PCR reactions according to Liang and Pardee (1997). cDNAs were synthesized using the anchored primers H-T11C (5'AAGCTTTTTTTTTTTC-3'), H-T11G (5'AAGCTTTTTTTTTTTG-3'), or H-T11A (5'AAGCTTTTTTTTTTTA-3'). As control for the L. (V.) braziliensis M2903-infected midgut, noninfected midgut RNA was mixed with $L$. (V.) braziliensis M2903 purified RNA. For cDNA amplification step (PCR reaction) and reamplification of gel purified fragments, we used a combination of the respective anchored primer with one of the following arbitrary primers (AP): AP1, 5'AGCCAGCGAA-3'; AP2, 5'-GACCGCTTGT-3'; AP3, 5'-AGGTGACCGT-3'; AP4, 5'GGTACTCCAC-3'; AP5, 5'-GTTGCGATCC-3'; AP6, 5'- GCAATCGATG-3'; AP7, 5'CCGAAGGAAT-3'. Fragments which were successfully reamplified after isolation from $6 \%$ acrylamide-7M urea gel, were cloned into the $\mathrm{pCR}$ 2.1 plasmid (TA Cloning kit, Invitrogen Corporation, Calrsbad, CA, USA) and sequenced.

$R A P D-P C R$ - cDNAs obtained from sugar and blood fed midguts RNA, as described above, were used in RAPD-PCR reactions with random primers (10 mers). Primers used were OPG3, OPG6 and OPG18 (Dias et al. 1998) (Operon Technologies, California, USA), kindly provided by Dr Edelberto Dias. Reactions were routinely performed in $50 \mu \mathrm{l}$ volume with 1X PCR buffer, $200 \mu \mathrm{M}$ dNTPs, 0.1$0.2 \mu \mathrm{M}$ of OPG 3, 6 or 16 primer, 2-5 ng cDNA and 0.5 units of KlenTaq $1^{\mathrm{TM}}$ (Ab Peptides Inc., St. Louis, MO, USA) DNA polymerase. A Thermo Cycler ABI9600 was set for 35 cycles of $94^{\circ} \mathrm{C} / 30$ sec, $30^{\circ} \mathrm{C} / 1 \mathrm{~min}, 72^{\circ} \mathrm{C} / 2 \mathrm{~min}$, followed by $10 \mathrm{~min}$ at $72^{\circ} \mathrm{C}$. PCR products were analyzed on $1 \% \mathrm{EtBr}-$ stained agarose gels.

Computer analysis - For BLAST we used the National Institutes of Health (NIH) internet homepage (www.ncbi.nlm.nih/BLAST) and each analysis was systematically done with expected (E) value never greater than 10 and in general between $10^{-7}$ and $10^{-2}$. FASTA analysis was performed with the GCG (Genetics Computer Group, WI, USA) package.

\section{RESULTS}

Identification of ESTs - We identified 59 ESTs, with lengths ranging from 90 to over 500 nucleotides, from single pass random sequencing of 120 clones isolated from two expression libraries of abdomen and head/thorax constructed from sugar fed females of L. longipalpis. Analysis of various sequences has provided us a first look at a variety of genes expressed by this insect vector. Strong similarity with known protein/DNA sequences from insects such as Drosophila sp., A. gambiae and Ae. aegypti was found in 32 clones (Table I).

Differentially expressed genes - Midguts from sugar and blood fed female insects were dissected and total RNA purified.The cDNA obtained by RTPCR was separated on sequencing-like acrylamide gel electrophoresis, and differential bands extracted, purified, reamplified and cloned (as indicated in Materials and Methods) into pCR2.1 vector. We also performed RAPD-PCR with sugar and blood fed midgut cDNAs. RAPD-PCR products were separated on agarose gel and the differential bands obtained were purified and cloned as described above. After selection of positive clones from DDRT and RAPD, the various cDNA inserts were sequenced and analysed by BlastX and/or FASTA.

We identified three cDNAs that may represent genes induced by the presence of blood or the parasite. The first was a putative gut-specific chitinase similar to another gut-specific, blood regulated chitinase from the mosquito A. gambiae. The second a vacuolar (V)-ATPase which was identified from $L$. (V.) braziliensis-infected midgut and showed homology to other insect V-ATPases. The third, a MAP kinase homologous to the p38 MAP kinase from $D$. melanogaster, was also identified from $L$. (V.) braziliensis-infected midguts (Table II).

\section{DISCUSSION}

We are studying variations in protein expression patterns taking place within the sand fly $L$. longipalpis midgut upon blood-feeding and infection. We are also interested in the characterization of ESTs from these insects to generate a $L$. longipalpis cDNA bank.

We have obtained two expression libraries from the abdomen and head/thorax from female $L$. longipalpis fed on a sugar diet (Ortigão et al. 1997) and isolated approximately 130 clones. By single pass random sequencing of more than 120 of the clones we identified several cDNAs which have shown homology to known proteins and genes of various insects (Table I). In spite of the fact that some of the clones obtained are of constitutive proteins, these can be used in studies aimed at characterizing molecular evolutionary relationships between different species of sand flies and between sand flies and other insects. This is the case for clone M17 (Table I) which has shown homology to a fast evolving gene from Drosophila, anon2C9 (Schmid \& Tautz 1997) and clone Y41 a homologue to the Dhr6 gene from D. melanogaster. Dhr6 
TABLE I

Expressed sequence tags obtained from cDNA libraries of Lutzomyia longipalpis adult females fed on sugar. Libraries were made from either head/thorax or abdomen

\begin{tabular}{|c|c|c|}
\hline Clone ID & Size & Homology \\
\hline Y2 & $360 \mathrm{bp}$ & ATP dependent RNA helicase \\
\hline Y10 & $60 \mathrm{bp}$ & Elastin-like protein \\
\hline Y11 & $340 \mathrm{bp}$ & Cytocrome oxidase $\mathrm{C}$ subunit II \\
\hline Y27 & $200 \mathrm{bp}$ & Ribosomal protein $\mathrm{S} 8$ \\
\hline Y28 & - & 16S RNA (FASTA) \\
\hline Y30R & - & Drosophila melanogaster gene alt 2 \\
\hline Y30 & $190 \mathrm{bp}$ & Dienoyl-CoA isomerase/hidratase \\
\hline Y31 & $181 \mathrm{bp}$ & 16S RNA (FASTA) \\
\hline Y32R & $375 \mathrm{bp}$ & Anopheles gambiae mitochondrial DNA (FASTA) \\
\hline Y33 & $375 \mathrm{bp}$ & Zinc finger protein \\
\hline Y35 & $372 \mathrm{bp}$ & Zinc finger protein \\
\hline Y36 & $369 \mathrm{bp}$ & 16S RNA (FASTA) \\
\hline Y38 & $443 \mathrm{bp}$ & 16S RNA (FASTA) \\
\hline Y39 & - & Cytocrome oxidase I \\
\hline Y41 & $200 \mathrm{bp}$ & Ubiquitin conjugating enzyme/RAD6 homologue \\
\hline Y42 & $322 \mathrm{bp}$ & 16S RNA (FASTA) \\
\hline M4 & $210 \mathrm{bp}$ & APC binding protein \\
\hline M5 & $140 \mathrm{bp}$ & Splicing factor \\
\hline M6 & $204 \mathrm{bp}$ & DNA binding protein \\
\hline M8 & & 16S RNA (FASTA) \\
\hline M9 & $190 \mathrm{bp}$ & Arabidopsis thaliana $\mathrm{F} 17 \mathrm{~F} 8.11$ sequence \\
\hline M11 & 179 bp & 16S rRNA A. gambiae (FASTA) \\
\hline M13 & $185 \mathrm{bp}$ & NADH A. gambiae (FASTA) \\
\hline M14 & $240 \mathrm{bp}$ & Serine hydroxymethyltransferase \\
\hline M17 & $386 \mathrm{bp}$ & Anon2C9 (fast evolving gene)/antennal-specific \\
\hline M18 & $305 \mathrm{bp}$ & 60 S Ribosomal protein L7A \\
\hline M19 & $222 \mathrm{bp}$ & Guanine nucleotide binding protein \\
\hline M22 & $267 \mathrm{bp}$ & Fumarylacetoacetase \\
\hline
\end{tabular}

Clones randomly isolated from L. longipalpis expression libraries were submitted to one round of sequencing (see text). Columns indicate the name of the clone (Clone ID), number of base pairs of inserted cDNA fragment (size) and homology found with sequences from Genebank, respectively. Sequences that did not find a match through the BLAST analysis were identified using FASTA (GCG), as indicated.

TABLE II

Clones identified through differential display reverse transcriptase-polymerase chain reaction (DDRT-PCR) and randomly amplified polymorphic DNA (RAPD-PCR)

\begin{tabular}{|c|c|c|c|}
\hline Clone ID & Size & Homology & Nature \\
\hline DDRT1.35 & 530 bp & Gut-specific chitinase & induced \\
\hline DDRT1.30 & $203 \mathrm{bp}$ & Ubiquitin/40S ribosomal protein & constitutive \\
\hline DDRT 1.56 & $250 \mathrm{bp}$ & Glutamine synthetase & \\
\hline DDRT 1.63 & $159 \mathrm{bp}$ & Laminin receptor/Ribosome assoc. ptn. & \\
\hline RAPD7.1 & $172 \mathrm{bp}$ & Ubiquitin conjugating enzyme & constitutive \\
\hline DDRTA1 & 150 bp & V-ATPase subunit $\mathbf{C}$ & induced \\
\hline DDRTA4 & $200 \mathrm{bp}$ & Mitogen activated protein kinase & induced \\
\hline DDRT B8 & $120 \mathrm{bp}$ & Drosophila melanogaster CG10939 & \\
\hline DDRT B12 & $110 \mathrm{bp}$ & D. melanogaster pyd gene & \\
\hline
\end{tabular}

Clones in this table were isolated through DDRT-PCR and RAPD-PCR. cDNAs were synthesized from RNAs purified from sugar, uninfected blood and infected blood fed adult female insects. Columns indicate the name of the clone (Clone ID); number of base pairs (size) of differential cDNA bands extracted from differential display gels; homology, found with sequences from Genebank; and status of the cDNA characterized, as constitutive or induced by the presence of blood (bold prints). Induced clones appear to be gut-specific (data not shown). Other clones include constitutively expressed proteins, such as ubiquitin protein, and proteins of still undefined character. 
itself is homologous to a protein involved in DNA repair and sporulation in the yeast Saccharomyces cerevisiae (Koken et al. 1991a,b). Other ESTs include: laminin receptor, glutamine synthetase, zinc finger protein, DNA binding protein, guanine nucleotide binding protein, ATP helicase. These are undergoing further investigation.

Since its widespread introduction as a powerful technique to study different patterns of gene expression in several models, DDRT-PCR has been successfully applied to identify and characterize cDNA in hematophagous insect disease vectors (Dimopoulos et al. 1996, Zurita et al. 1997). We applied DDRT to investigate changes in midgut protein expression levels in the sand fly $L$. longipalpis by comparing RNA isolated from sugar fed, blood fed and L. (V.) braziliensis-infected midguts. Among the nine sequences (Table II) with homology to known genes that were identified, three appear to be expressed exclusively in the midguts of sand flies after a blood meal (DDRT1.35) or infection (DDRTA1 and DDRTA4). We are currently focusing our attention in the further characterization of these cDNA sequences. The first cDNA, a putative gut-specific chitinase, is similar to gut-specific chitinases characterized from A. gambiae (Shen \& Jacobs-Lorena 1997) and from the beetle Phaedon cochleariae (Girard \& Jouanin 1999). Intestinal chitinases from hematophagous insects play a role in the formation and degradation of the type I peritrophic matrix (PM). This PM can act as a barrier that the parasite must overcome to reach the epithelial cell wall. Pimenta et al. (1997) have shown that the sand fly PM also plays a role protecting Leishmania amastigotes from degradation by digestive enzymes. Studies on how blood meal, time and other parameters may alter the expression of this $L$. longipalpis chitinase are currently under way.

The second, a vacuolar V-ATPase subunit C cDNA has shown high degrees of homology with their counterpart proteins from insects such as $D$. melanogaster, Manduca sexta and the tick Amblyomma americanum. A gut-specific V-ATPase subunit, whose expression is modulated by blood, has also been identified from A. gambiae (Dimopoulos et al. 1996). V-ATPases are heteromeric proton-translocating enzymes composed of a catalytic and a transmembrane spanning region domains which are found in all eukaryotes and possess a broad range of biological functions (Merzendorfer et al. 1997, Dow et al. 1997, Forgac 1998). In insects V-ATPases are able to regulate intracellular $\mathrm{pH}$ levels and also to energize the epithelial membranes.

Gontijo et al. (1998) observed that reacidification of L. longipalpis midgut after digestion of a blood meal could be explained by excreted material from Malpighian tubules. Before a blood meal, midgut $\mathrm{pH}$ was measured at approximately $\mathrm{pH} 6$ and the hindgut at a $\mathrm{pH}$ lower than $\mathrm{pH}$ 6. Upon taking a blood meal, $\mathrm{pH}$ in the gut increases as a result of the $\mathrm{pH} 7.4$ of blood. After complete digestion, $\mathrm{pH}$ may decrease to levels prior to the blood meal. However, they also assumed that a reflux in the hindgut could be responsible for the drop in the midgut $\mathrm{pH}$. The reacidification of the midgut would stimulate metacyclogenesis of Leishmania parasites taken with an infective blood meal as seen with cultured Leishmania parasites (Zakai et al. 1998). In M. sexta, a V-ATPase homologue is known to be concentrated in the apical membrane of the midgut where it functions in $\mathrm{H}^{+}$secretion during the antiport $\mathrm{K}^{+} / \mathrm{H}^{+}$exchange (Graf et al. 1994, Jäger et al. 1996). Altogether these observations suggest that expression of V-ATPases in the midgut of sand fly vectors may participate in events leading to metacyclogenesis of Leishmania parasites.

The third cDNA codes for a MAP kinase with homology to the D. melanogaster D-MKK3 gene (Han et al. 1998). MAP kinases participate in a cellular signaling process to activate the cascade mechanisms of the insect innate immune system.

This is the first report that shows the characterization of gut specific cDNAs from the sand fly vector L. longipalpis. The possibility that these molecules participate closely in mechanisms of vector-parasite interaction as well as defense mechanisms that may be displayed by $L$. longipalpis upon Leishmania infection is currently being investigated.

\section{ACKNOWLEDGEMENTS}

To Dr Edelberto Dias, CPqRR-Fiocruz, for the gift of the oligonucleotides used in the Randomly Amplified Polymorphic DNA-PCR reactions, to Dr Hooman Momen, IOC-Fiocruz for critical reading of the manuscript, and to Robson C Silva for technical assistance.

\section{REFERENCES}

Billingsley PF 1994. Approaches to vector control: new and trusted. 2. Molecular targets in the insect midgut. Trans R Soc Trop Med Hyg 88: 136-140.

Butcher BA, Turco SJ, Hilty BA, Pimenta PF, Panuzio M, Sacks DL 1996. Deficiency in $\beta 1,3-\mathrm{Ga}-$ lactosyltransferase of a Leishmania major lipophosphoglycan mutant adversely influences the Leishmania-sand fly interaction. J Biol Chem 271: 20573-20579.

Chakrabarti D, Reddy GR, Dame JB, Almira EC, Laipis PJ, Ferl RJ, Yang TP, Rowe TC, Schuster SM 1994. Analysis of expressed sequence tags from Plasmodium falciparum. Mol Biochem Parasitol 66: 97-104.

Charlab R, Valenzuela JG, Rowton ED, Ribeiro JMC 1999. Toward an understanding of the biochemical 
and pharmacological complexity of the saliva of a hematophagous sand fly Lutzomyia longipalpis. Proc Natl Acad Sci USA 96: 15155-15160.

Dias ES, Fortes-Dias CL, Stiteler JM, Perkins PV, Lawyer PG 1998. Random amplified polymorphic DNA (RAPD) analysis of Lutzomyia longipalpis laboratory populations. Rev Inst Med Trop São Paulo 40: 49-53.

Dillon RJ, Lane RP 1999. Detection of Leishmania lipophosphoglycan binding proteins in the gut of the sand fly vector. Parasitology 118: 27-32.

Dimopoulos G, Richman A, Della-Torre A, Kafatos FC, Louis C 1996. Identification and characterization of differentially expressed cDNAs of the vector mosquito, Anopheles gambiae. Proc Natl Acad Sci USA 93: 13066-13071.

Dow JAT, Davies SA, Guo Y, Graham S, Finow ME, Kaiser K 1997. Molecular genetic analysis of VATPase function in Drosophila melanogaster. J Exp Biol 200: 237-245.

Edwards MJ, Lemos FJ, Donnelly-Doman M, JacobsLorena M 1997. Rapid induction by a blood meal carboxypeptidase gene in the gut of the mosquito Anopheles gambiae. Insect Mol Biol 27: 1063-1072.

Forgac M 1998. Structure, function and regulation of the vacuolar $(\mathrm{H}+)$-ATPases (Review). FEBS letters 440: 258-263.

Girard C, Jouanin L 1999. Molecular cloning of a gutspecific chitinase cDNA from the beetle Phaedon cochleriae. Insect Biochem Mol Biol 29: 549-556.

Gontijo NF, Almeida-Silva S, Costa FF, Mares-Guia ML, Williams P and Melo MN 1998. Lutzomyia longipalpis: $\mathrm{pH}$ in the gut, digestive glycosidases, and some speculations upon Leishmania development. Exp Parasitol 90: 212-219.

Graf R, Lepier, A, Harvey, WR, Wieczorek H 1994. A novel 14-kDa V-ATPase subunit in the tobacco hornworm midgut. J Biol Chem 269: 3767-3774.

Han ZS, Enslen H, Hu X, Meng X, Wu I-H, Barrett T, Davis RJ, Ip YT 1998. A conserved p38 mitogenactivated protein kinase pathway regulates Drosophila immunity gene expression. Mol Cell Biol 18: 3527-3539.

Jäger D, Novak FJS, Harvey WR, Wieczorek H, Klein $\mathrm{U}$ 1996. Temporal and spatial distribution of $\mathrm{V}$ ATPase and its mRNA in the midgut of the moulting Manduca sexta. J Exp Biol 199: 1019-1027.

Koken M, Reynolds P, Bootsma D, Hoeijmakers J, Prakash S, Prakash L 1991a. Dhr6, a Drosophila homolog of the yeast DNA-repair gene RAD6. Proc Natl Acad Sci USA 88: 3832-3836.

Koken HMM, Reynolds P, Jaspers-Dekker I, Prakash L, Prakash S, Bootsma D, Hoeijmakers J 1991 b. Structural and functional conservation of two human homologs of the yeast DNA repair gene RAD6. Proc Natl Acad Sci USA 88: 8865-8869.

Lerner EA, Shoemaker CB 1992. Maxadilan: cloning and functional expression of the gene encoding this potent vasodilator peptide. J Biol Chem 267: 1062 1066.

Lerner EA, Ribeiro JM, Nelson RJ, Lerner MR 1991. Isolation of maxadilan, a potent vasodilatory pep- tide from the salivary glands of the sand fly Lutzomyia longipalpis. J Biol Chem 266: 11234.

Liang P, Pardee AB 1997. Differential Display. A General Protocol. In P Liang, AB Pardee (eds), Differential Display Methods and Protocols, Humana Press, Totowa, New Jersey, p. 3-11.

Mahoney AB, Sacks DL, Saraiva E, Modi G, Turco SJ 1999. Intra-species and stage-specific polymorphisms in lipophosphoglycan structure control Leishmania donovani-sand fly interactions. Biochemistry 38: 9813-9823.

Merzendorfer H, Graf R, Huss M, Harvey WR, Wieczorek H 1997. Regulation of proton-translocating V-ATPases. J Exp Biol 200: 225-235.

Muller HM, Catteruccia F, Vizioli J, della Torre A, Crisanti A 1995. Constitutive and blood meal-induced trypsin genes in Anopheles gambiae. Exp Parasitol 81: 371-385.

O’Brochta DA, Atkinson PW 1997. Recent developments in transgenic insect technology. Parasitol Today 13: 99-104.

Ortigão M, Vilela M, Rangel E, Traub-Cseko YM 1997. Expressed sequence tags sequencing of Lutzomyia longipalpis. Mem Inst Oswaldo Cruz 92 (Suppl. I): 316.

Pimenta PFP, Modi GB, Pereira ST, Shahabuddin M, Sacks DL 1997. A novel role for the peritrophic matrix in protecting Leishmania from the hydrolytic activities of the sand fly midgut. Parasitology 115 : 359-369.

Pimenta PFP, Saraiva EMB, Rowton E, Modi GB, Garraway LA, Beverley SM, Turco SJ, Sacks DL 1994. Evidence that the vectorial competence of phlebotomine sand flies for different species of Leishmania is controlled by structural polymorphisms in the surface lipophosphoglycan. Proc Nat Acad Sci USA 91: 9155-9159.

Rabelo EML, Franco GR, Azevedo VAC, Pena HB, Santos TM, Meira WSF, Rodrigues NA, Ortega JM, Pena SDJ 1997. Update of the gene discovery program in Schistosoma mansoni with expressed sequence tag approach. Mem Inst Oswaldo Cruz 92: 625-629.

Sacks DL, Modi G, Rowton E, Apath G, Epstein L, Turco SJ, Beverley SM 2000. The role of phosphoglycans in Leishmania-sand fly interactions. Proc Natl Acad Sci USA 97: 406-411.

Sacks DL, Saraiva EM, Rowton E, Turco SJ, Pimenta PF 1994. The role of the lipophosphoglycan of Leishmania in vector competence. Parasitology 108: S55S62.

Saraiva EMB, Pimenta PFP, Brodin TN, Modi GB, Sacks DL 1995. Changes in lipophosphoglycan and gene expression associated with the development of Leishmania major in Phlebotomus papatasi. Parasitology 111: 275-287.

Schmid KJ, Tautz D 1997. A screen for fast evolving genes from Drosophila. Proc Natl Acad Sci USA 94: 9746-9750.

Shen Z, Jacobs-Lorena M 1997. Characterization of a novel gut-specific gene from the human malaria vector Anopheles gambiae. J Biol Chem 272: $28895-$ 
28900.

Shen Z, Dimopoulos G, Kafatos FC, Jacobs-Lorena M 1999. A cell surface mucin specifically expressed in the midgut of the malaria mosquito Anopheles gambiae. Proc Natl Acad Sci USA 96: 5610-5615.

Soares MB, Titus RG, Shoemaker CB, David JR, Bozza M 1998. The vasoactive peptide maxadilan from sand fly saliva inhibits TNF-alpha and induces IL-6 by mouse macrophages through interaction with the pituitary adenylate cyclase-activating polypeptide (PACAP) receptor. J Immunol 160: 1811-1816.

Warburg A, Saraiva E, Lanzaro GC, Titus RG, Neva F 1994. Saliva of Lutzomyia longipalpis sibling species differs in its composition and capacity to enhance leishmaniasis. Philos Trans R Soc Lond B Biol
Sci 345: 223-230.

Wermelinger ED, Rangel EF, Souza NA, Barbosa AF 1987. A practical method for mass breeding of sandflies in the laboratory: Lutzomyia intermedia (Lutz \& Neiva, 1912) and Lutzomyia longipalpis (Lutz \& Neiva, 1912) (Diptera, Psychodidae). Mem Inst Oswaldo Cruz 82: 441-442.

Zakai HA, Chance ML, Bates PA 1998. In vitro stimulation of metacyclogenesis in Leishmania braziliensis, L. donovani, L. major and L. mexicana. Parasitology 116: 305-309.

Zurita M, Reynaud E, Kafatos FC 1997. Cloning and characterization of cDNAs preferentially expressed in the ovary of the mosquito, Anopheles gambiae. Insect Mol Biol 6: 55-62. 